\title{
Significance of recent onset nocturnal enuresis in adult men: a prospective study
}

\author{
AM Abeygunasekera ${ }^{1}$, RJ Jayasinghe ${ }^{2}$, MT Duminda ${ }^{2}$, THT Chamintha ${ }^{2}$ and RWP Guruge ${ }^{2}$
}

(Index words : Bladder outflow obstruction, investigation, lower urinary tract symptoms, management)

\begin{abstract}
Introduction Although literature on childhood nocturnal enuresis and its persistence into adulthood is abundant, recent onset nocturnal enuresis in adults is a poorly studied symptom.

Objective To determine the significance of recent onset nocturnal enuresis in adult males in relation to lower urinary tract pathology, and its treatment.

Methods All men with recent onset nocturnal enuresis attending a urology unit over a period of 12 months were evaluated prospectively. Their treatment and outcome were recorded.

Results There were 30 patients (mean age 64 years). Ultrasonography revealed upper urinary tract dilatation in 22 patients. Another six patients had post-void residual urine volume over $500 \mathrm{~mL}$ without upper tract dilatation. Only two patients did not have ultrasonographic evidence of bladder outflow obstruction. Elevated blood urea was noted in 14 patients. Twenty patients underwent transurethral resection of the prostate (TURP) and one patient with balanitis xerotica obliterans had circumcision and meatotomy. Three patients were taught clean intermittent self catheterisation, and three patients preferred indwelling urethral catheters. One patient while awaiting TURP died of a myocardial infarction. Eight patients, who were treated with $\alpha$-adrenergic antagonists initially, required further intervention later as the response to medical therapy was poor.
\end{abstract}

Conclusions Recent onset nocturnal enuresis in adult males is a symptom closely associated with significant lower urinary tract pathology requiring early urological intervention. Considering its impact on management it is reasonable to classify recent onset nocturnal enuresis as a lower urinary tract symptom in adult men and including it in symptom scores used to assess bladder outflow obstruction.

\section{Introduction}

Enuresis has been defined as an involuntary discharge of urine. Incontinence that occurs at night during sleep is referred to as nocturnal enuresis (NE). NE occurring in adults is seen in two contexts: persistent primary $\mathrm{NE}$, due to the continuation of childhood NE; and secondary or adult onset NE [1]. Recent onset NE without daytime incontinence in adult males falls into the latter group.
Persistent primary NE in adults occurs in more than $1 \%$ of men, and the incidence of organic disease does not appear to be appreciably greater for adults with persistent primary NE than for children with NE, although urodynamic abnormalities have been identified more commonly in patients with persistent primary NE [2].

Recent onset NE without daytime incontinence is considered uncommon, and is not generally a solitary symptom but occurs more commonly in association with other disturbances of micturition [3,4]. Its significance is uncertain due to a paucity of studies specifically evaluating recent onset NE without daytime incontinence. Although it has been described as a characteristic feature of high pressure chronic retention of urine, the significance and evaluation of recent onset $\mathrm{NE}$ are not well defined in the literature $[5,6]$. We decided to assess the symptom of recent onset NE in adult men in a prospective study.

\section{Patients and methods}

The study population consisted of a consecutive sample of 30 men over the age of 18 years who had recent onset nocturnal enuresis attending the Urology Unit, Teaching Hospital Karapitiya, over a period of 12 months starting from 1 January 2003. Patients with associated urinary incontinence while awake (daytime incontinence) were excluded from the study. All of them were evaluated prospectively while undergoing treatment. The management of patients with recent onset NE included a detailed history and physical examination, midstream urine culture, ultrasonography of the urinary tract (including post-void bladder residual urine volume), blood urea estimation and cystourethroscopy followed by appropriate intervention. No patient was on medication active on the lower urinary tract before evaluation and none had undergone previous lower urinary tract surgery.

\section{Results}

The mean age of patients was 64 years (range 22-85). Only four were aged less than 50 years $(22,24,28$ and 38 years). The symptom of NE in these patients was mainly a small leakage of urine during sleep. In eight patients the leakage happened during an afternoon nap too. However, there was no urinary incontinence when the patient was awake. No patient in the series had

${ }^{1}$ Urological Surgeon, ${ }^{2}$ Senior House Officer, Urology Unit, Teaching Hospital Karapitiya, Sri Lanka.

Correspondence: AMA, Tel: +9410112763427 and +94 1077 7903130, e-mail: <amabey@sltnet.lk> (Competing interests: none declared). Received 3 February 2004 and accepted 10 February 2004. 
treatment for enuresis as a child. Twenty seven patients had associated lower urinary tract symptoms. Poor stream, which was noted in 23 patients, was the commonest accompanying lower urinary tract symptom.

On examination, 26 patients were found to have a painless palpable bladder, at times extending up to or even beyond the umbilicus. Bilateral hydronephrosis and hydroureter with grossly increased post-void residual urine volume was noted in 22 patients, and six patients had post-void residual urine volumes over $500 \mathrm{~mL}$ without upper urinary tract dilatation. Raised blood urea was found in 14 patients and all of them had upper urinary tract dilatation. None of the patients had an active urinary tract infection.

Three patients whose blood urea was over $15 \mathrm{mmol} / \mathrm{L}$ had initial urethral catheterisation to improve the renal function before surgical intervention. One of them awaiting TURP developed a myocardial infarction and died of pulmonary oedema. Fifteen patients were treated with TURP. One patient had severe phimosis and meatal stenosis due to balanitis xerotica obliterans and underwent circumcision and meatotomy. Eight patients with ultrasonographic evidence of poor bladder emptying were treated with $\alpha$-adrenergic antagonists. Five of them had serious co-morbidity precluding surgery and three patients refused to undergo surgery. However, all eight patients treated with $\alpha$-adrenergic antagonists continued to have urinary symptoms including NE and poor bladder emptying, as evidenced by follow up ultrasonography. Hence five of the medically treated patients accepted the risk of surgery and underwent TURP successfully whereas the other three were offered long term indwelling urethral catheterisation.

Three of the four patients younger than 50 years, who had poor bladder emptying but did not have evidence of mechanical obstruction of the lower urinary tract, were thought to be having neurological bladder dysfunction, and were trained to do clean intermittent selfcatheterisation. The two patients who did not have ultrasonographic evidence of bladder outflow obstruction (BOO) were given a trial of $\alpha$-adrenergic antagonists, with relief of symptoms in one. All 21 patients who underwent surgery and three patients who started performing clean intermittent self catheterisation were totally free of NE. Their follow up ultrasound scans revealed a normal upper urinary tract.

\section{Discussion}

Although all children over the age of six years with NE should undergo a urological evaluation, the vast majority will be found to have no significant urological abnormality [1]. The pathophysiology of primary persistent NE in adults is the same as childhood NE $[1,4,7]$. In our study recent onset NE was almost always associated with significant urological abnormality as indicated by a high post-void residual urine volume in 28 patients and upper urinary tract dilatation in 22. The findings of this study, indicate a different pathophysiology for recent onset NE in adult males.

The term "lower urinary tract symptoms" is used as a collective noun for any constellation of symptoms related to the lower urinary tract at any age and either sex [8]. Still recent onset NE is not classified as a lower urinary tract symptom although one study has indicated its association with bladder neck hypertrophy [6]. There are two main aims in assessing men with symptoms of BOO $[9,10]$. The first is the evaluation of severity of the patient's symptoms and their impact upon quality of life. The second is to generate a differential of management alternatives, based on an educated guess about the likely response to a given therapy. To this end a variety of symptom scores have been developed [10]. None of these scoring systems include the symptom of recent onset NE. In our study 22 patients with recent onset NE had upper urinary tract dilatation with an impending threat to renal function, necessitating early urological intervention. Therefore, it may be appropriate to classify recent onset $\mathrm{NE}$ as a lower urinary tract symptom and incorporate it into the symptom scores used to evaluate patients with BOO.

Advances in medical treatment allow many men with $\mathrm{BOO}$ to be treated in the community by primary care physicians [11]. Since the presence of recent onset NE may indicate an imminent threat to renal function, such patients should be referred to a urology unit without delay. Primary care physicians who treat BOO need to be aware of this. Many urologists do not perform imaging of the upper urinary tract routinely because tumour and kidney stones are not more frequent in men with benign prostatic enlargement than in healthy men [11]. In our study 22 patients with recent onset NE had upper urinary tract dilatation. Therefore, in units where upper urinary tract imaging is done selectively recent onset NE should be considered a criterion for upper tract imaging.

Medical management is generally first recommended for patients with moderate and severe BOO, if they are bothered by symptoms [12]. In our study none of the eight patients with BOO and who were treated with $\alpha$-adrenergic antagonists had improvement of symptoms or postvoid residual urine volumes even after 4 to 6 weeks of therapy. If after 1 month of treatment with an $\alpha$-blocker the patient's quality of life is still appreciably impaired, the possibility of surgery should be considered [13]. From the results of our study, it is clear that medical management is not satisfactory enough to treat BOO associated with recent onset $\mathrm{NE}$.

In conclusion, recent onset NE in adult males is a symptom closely associated with significant lower urinary tract pathology requiring early urological intervention. Considering its impact on management it is reasonable to classify recent onset $\mathrm{NE}$ as a lower urinary tract symptom in adult men and including it in symptom scores used to assess BOO. 


\section{References}

1. Koff SA. Enuresis. In: Walsh PC, Retic AB, Vaughan ED, Wein AJ, eds. Campbell's Urology. 7th edn. Philadephia: WB Saunders, 1998; 266-73.

2. Torrens MJ, Collins CD. The urodynamic assessment of adult enuresis. British Journal of Urology 1975; 47: 433-40.

3. Burgio KL, Locher JL, Ives DG, Hardin JM, Newman $\mathrm{AB}$, et al. Nocturnal enuresis in community-dwelling older adults. Journal of the American Geriatric Society 1996; 44: 139-43.

4. Sakamoto K, Blaivas JG. Adult onset nocturnal enuresis. Journal of Urology 2001; 165: 1914-7.

5. George NJR, O’ Reilly PH, Barnard RJ, Blacklock NJ. High pressure chronic retention. British Medical Journal 1983; 286: 1780-3.

6. Miller A. Adult enuresis. British Journal of Urology 1966; 38: $697-9$.
7. Norgaard JP, Pederson EB, Dijurhuus JC. Diurnal antidiuretic-hormone levels in enuresis. Journal of Urology 1985; 134: 1029-31.

8. Abrams P. New words for old: lower urinary tract symptoms for "prostatism". British Medical Journal 1994; 308: 929-30.

9. Phipps S, McNeill A. Assessing men with benign prostatic obstruction-time for a new prostatic paradigm. Urology News 2002; 7: 6-12.

10. Hines JEW. Symptom indices in bladder outlet obstruction. British Journal of Urology 1996; 77: 494-501.

11. Thorpe A, Neal D. Benign prostatic hyperplasia. Lancet 2003; 361: 1359-66.

12. Vaughan ED. Medical management of benign prostatic hyperplasia-are two drugs better than one? New England Journal of Medicine 2003; 349: 2449-51.

13. Abrams P. Managing lower urinary tract symptoms in older men. British Medical Journal 1995; 310: 1113-7. 